\title{
Practical challenges and digital learning: getting the balance right for future-thinking.
}

Dharmasasmita, A., Puntha, H., and Molthan-Hill, P., (2017),"Practical challenges and digital learning: getting the balance right for future-thinking ", On the Horizon, Vol. 25 Iss 1 pp. 33 - 44

Permanent link to this document:

http://dx.doi.org/10.1108/OTH-04-2016-0018

\section{$\underline{\text { Abstract }}$}

Purpose: This paper aims to present a food-themed project at Nottingham Trent University, the Sustainability in Practice $(\mathrm{SiP})$ Certificate, a supra-disciplinary approach involving a collaborative enquiry into food sustainability through a flexible online course open to all staff and students. The focus will be on the SiP Challenge Days.

Design/Methodology/Approach: The paper will describe the pedagogical approach of the certificate's online and offline components, the various activities undertaken by participants and the digital tools employed to encourage collaboration and skills development.

Findings: The Challenge Days have, so far, proven to be effective in inspiring students to be creative in solving sustainability challenges, especially through supradisciplinary collaboration.

Research Limitations/Implications: This is a new project hence participation has been relatively small. However, organisation of Challenge Days for the next academic year is already in progress including two new themes. These additions should offer extra dimensions of experience for the participants as well as a richer future dataset.

Social Implications: Through collaboration across disciplines, the students have a wider understanding of contemporary sustainably issues as they play a pro-active role in solving these current challenges.

Originality/Value: The practice element of this online module and the crowdsourcing of sustainable solutions within SiP are described in detail in this paper. Special attention is given to how the design of SiP equips students with the skills needed to solve sustainable challenges.

\section{Key words:}

Learner-generated resources, systems thinking, adaptive competencies for sustainability, crowdsourcing, sustainable solutions, online course, hard skills, soft skills, supradisciplinary.

\section{$\underline{\text { Introduction }}$}

'Real world' concerns rarely arrive in discrete disciplinary packages and the Sustainability in Practice (SiP) Certificate at Nottingham Trent University (NTU) reflects this with a supradisciplinary enquiry into food sustainability in the form of a flexible online course open to all staff and students. Food sustainability was selected within NTU's Green Academy Project (a UK Higher Education Academy (HEA) Change Academy) as a unifying theme that is a 
complex, critical global challenge (Foresight 2011) of relevance to all disciplines. The certificate itself attempts by design, to bridge utopian and utilitarian approaches to education combining transferable skills with sustainability literacy, an approach advocated by leading authors (Leal Filho et al 2015, Dale and Newman 2005).

The SiP Certificate aims to introduce participants to sustainability in four ways:

1) Introduce the basic concept of sustainability to participants who are new to it;

2) For participants who are already aware of the sustainability concept, to enhance this through application of multi and supra-disciplinary and systems thinking;

3) Enable students to be co-creators in crowdsourcing sustainable solutions;

4) Enable students to gain skills needed to solve sustainability problems.

Aims (1) and (2) are addressed in detail in Puntha et al (2015) and Molthan-Hill et al (2016). The main objective of this paper is to address (3), and (4), first looking at student crowdsourcing of sustainability solutions before moving on to the fostering of sustainability skills. Particular reference will be made to 'Challenge Days' wherein students are given the opportunity to undertake practical sessions alongside their digital learning. Prior to discussing (3) and (4), we will comment upon the significance of the supra-disciplinary approach and the use of a digital platform.

\section{Overview of the Certificate}

The SiP Certificate is an online, multidisciplinary course automatically available to students campus-wide through the University Virtual Learning Environment (VLE) at NTU. The certificate is non-credit-bearing, but has been adapted and integrated into certain courses as a credit-bearing assessment. As sustainability education is a strategic aspiration of NTU (see section on fostering sustainability skills), the decision to make the certificate online, multidisciplinary and with a flexible completion timeline was to encourage as many students as possible to engage. SiP was the first project for NTU's Green Academy, an HEA initiative. It first ran in 2013/14 and was shortlisted for a Green Gown award in 2014

The certificate is comprised of 4 sessions and a final project assessment piece. The time commitment required to complete the certificate is estimated at 20 hours, including 30-60 minutes per session and up to 16 hours for the final project. Participants can complete the course in their own time alongside their usual course over a 6-month period between September and March of an academic year.

All students who complete the whole certificate (4 sessions plus a final project), receive a certificate of completion and have the certificate added to their HEAR (Higher Education Achievement Record). Students' final projects are assessed by academics from their discipline areas and are shortlisted for a competition wherein students are invited to vote for their favourite project via the Student Union 
website. All students who completed the course are invited to attend a certificate awards and exhibition evening in June where the shortlisted final projects are exhibited and prizes awarded.

Students who do not complete the certificate nevertheless gain at least a basic knowledge of sustainability which they can utilise within their course. SiP gives students an introduction to the subject as well as valuable transferable skills which are highlighted during the promotion of the certificate to encourage students to see the value of participating. Sustainability education is a strategic aim for the university and $\mathrm{SiP}$ is one means to encourage the embedding of sustainability within all courses.

Submitted final projects are offered to academics across the institution to use as teaching materials. In this way, the certificate enables the institution to meet its strategic sustainability education aspirations in two ways: it provides participating students the opportunity to gain a level of sustainability literacy from basic to advanced in a dedicated course, and provides other students with a range of opportunities to learn about sustainability within their usual course of study.

\section{Using a Multi-disciplinary Digital Platform}

Adopting an enquiry-based learning model (Levy and Petrulis 2012), SiP invites participants to address the question 'How do we feed the world sustainably?' Participants are encouraged to look at the 'whole picture', and view things from a multi-disciplinary perspective (Rogers et al 2015) with the view that they can critique current systems and come up with solutions (Leal Filho et al 2015). Dale and Newman (2005: 353) advocate for a multi-disciplinary approach arguing that the conventional 'mono-discipline curriculum has not prepared the graduates to address unexpected problems within a complex system'. Leal Filho et al (2015:124) argue that for ESD to work effectively, students (and educators) need to start asking difficult and uncomfortable questions including 'critically questioning systems, policies and routines that appear fundamentally unsustainable'. The design of the SiP stimulates students to do just that, for example through discussion forums in each session where students are encouraged to post a digital artefact, question or comment or respond to another participant's post. These discussions are facilitated and monitored by the Green Academy team, and some content and ideas are collated for potential use in teaching. As well as encouraging critique, this is one way SiP participants are co-creators for both offline and online curriculum, through learner-generated resources.

The online digital learning format offers an effective way to reach all students and staff without the logistics of timetabling, room booking and so on. Rogers et al (2015) similarly found an asynchronous approach to multidisciplinary ESD to be logistically easier yet valuable. The certificate also offers participants the experience of online learning, which for many is their first experience of a fully online course. There are also several advantages to housing the certificate as a learning room within the institutional VLE rather than an external platform; the access of students and the demographics of those students can be monitored. Furthermore, all students can be automatically enrolled making it more convenient for them 
to commence the certificate and encouraging people to view the certificate as part of the 'everyday' business of studying at the institution.

As students from any discipline can participate, the solutions they generate - sometimes working across disciplines - provide pieces to the overall puzzle of food sustainability. SiP was designed to encourage personal reflection, knowledge acquisition, the aforementioned skills development, and (for some participants) practical action with the aim of providing a meaningful and transformative learning experience. Table 1 illustrates the strategic design of the online sessions.

Table 1: Overview structure of the Certificate online content

\begin{tabular}{|l|l|l|l|}
\hline $\begin{array}{l}\text { Session } \\
\text { one }\end{array}$ & $\begin{array}{l}\text { Topic } \\
\text { Sudent experience of }\end{array}$ & $\begin{array}{l}\text { Aim } \\
\text { personal level }\end{array}$ & $\begin{array}{l}\text { Example activity } \\
\text { options for a chicken stir-fry }\end{array}$ \\
\hline $\begin{array}{l}\text { Session } \\
\text { two }\end{array}$ & $\begin{array}{l}\text { Sustainability and food in the } \\
\text { disciplines }\end{array}$ & $\begin{array}{l}\text { Facilitate disciplinary } \\
\text { understanding of } \\
\text { sustainability }\end{array}$ & $\begin{array}{l}\text { Source an online video which relates } \\
\text { to food, sustainability and the student's } \\
\text { discipline }\end{array}$ \\
\hline $\begin{array}{l}\text { Session } \\
\text { three }\end{array}$ & $\begin{array}{l}\text { Connections between } \\
\text { disciplines; identifying } \\
\text { challenges }\end{array}$ & $\begin{array}{l}\text { Facilitate multi- } \\
\text { disciplinary } \\
\text { understanding of } \\
\text { sustainability }\end{array}$ & $\begin{array}{l}\text { Source an online artifact (e.g. video, } \\
\text { journal/professional article) which } \\
\text { relates to food, sustainability and two } \\
\text { or more disciplines with reference to } \\
\text { the food life cycle }\end{array}$ \\
\hline $\begin{array}{l}\text { Session } \\
\text { four }\end{array}$ & Global and local solutions & $\begin{array}{l}\text { Identify disciplinary/ } \\
\text { multi-disciplinary } \\
\text { solutions to sustainability } \\
\text { challenges }\end{array}$ & $\begin{array}{l}\text { Source existing local or global } \\
\text { food sustainability solutions }\end{array}$ \\
\hline
\end{tabular}

Various digital pedagogies such as prezi presentations, quizzes, and online research are utilised within session activities, together with discussion forums and collaborative mapping. The digital platform encourages accessibility and a suite of resources relating to various disciplines enables participants to identify with the topic, for example social policy students can access articles about food banks, computing students can read a feature about food transport logistics. Each new session is released to the participant once they have completed the preceding session. Completion of the fourth and final session unlocks the dropbox for participants to submit their final-project.

The taught content increases in complexity as the certificate progresses with a view to encouraging the adaptive competence of supra-disciplinary perspective by the end. The term 'supra-disciplinary' is used here to indicate that the focus of $\mathrm{SiP}$ is at a level above disciplines; the certificate begins from the research question 'How can we feed the world in a sustainable way?' In order to fully engage with the certificate participants must address this question in a fluid and multi-perspective way, posing their own questions in order to contribute to the overall question. An example might be that in order to answer the overall question a participant may ask 'How can milk be produced in a sustainable manner?'. 
Multiple disciplinary (and personal) expertise may be needed to provide an adequate answer to this question of sustainable milk. In this way the various questions posed and solutions offered provide a multi-faceted supra-disciplinary meta-solution to the initial research question ${ }^{1}$. The sessions take participants on a journey of personal, disciplinary and multidisciplinary perspectives on food sustainability challenges before a final focus on creating solutions as a response to the supra-disciplinary question 'How can we feed the world sustainably?' The combination of personal, disciplinary, multi-disciplinary, supradisciplinary and occasional interdisciplinary learning is a unique experience for most $\mathrm{SiP}$ student participants within their time at university, and hence the certificate has the potential to provide not only new knowledge but a different perspective on disciplinary knowledge as well as the world. Most students, unless they are undertaking a Joint Honours course will rarely if ever take part in academic debate with students from other disciplines, learn knowledge from other disciplines (multi-disciplinary) or work together with students from other disciplines on a piece of a work (some students opt to do interdisciplinary projects). That the whole course stems from a supra-disciplinary enquiry is also a unique experience for most where they explore the jigsaw of how different knowledge addresses different questions within an overall enquiry.

Diamond and Irwin (2013) made two recommendations following their exploration of different staff practices using e-learning for sustainability literacy; (1) that e-learning should support student-centred modes of learning to facilitate student identity, cognitive processes and confidence and; (2) that e-learning should be used to support the personal identity, skill development and professional confidence of students to apply skills in real-world contexts (paraphrased from Diamond and Irwin 2013). These uses are in contrast to using e-learning for other uses such as information transmission and are in alignment with the uses of elearning within SiP.

\section{$\underline{\text { Students as co-creators in crowdsourcing sustainability solutions }}$}

Despite the high engagement in the discussion forums, feedback from participant focus groups indicated a desire to go beyond theoretical discussion; they wanted to get actively involved in some practical sustainability work, as one student commented, "to put the 'practice' into 'Sustainability in Practice'". Therefore, the 'Sustainability Challenge Days' were developed for the third academic year of running the certificate. These days incorporate in-person discussion, volunteering, and collaborative group learning as well as completion of the online course. It was intended that the day would appeal to different styles of learners and would also present an enticement to students who wanted to complete the certificate quickly and efficiently. Challenge Days have thus far included a morning of individual certificate completion punctuated by group discussion and an afternoon of hands-

\footnotetext{
${ }^{1}$ The term 'supra-disciplinary' was first encountered by one of the authors at a symposium (Baressi et al, 2014) by Paul Baressi, and has been adapted for use within SiP to explain the nature of the collaborative enquiry constituted by the certificate.
} 
on volunteering within the campus-based allotment. Table 2 below demonstrates the Schools of the students who attended the Challenge Day. Feedback has been encouraging and further Challenge days are planned with different themed activities such as upcycling and turning movement into energy for the coming academic year.

Table 2: Overview of the academic schools of the student participants

\begin{tabular}{|l|l|}
\hline $\begin{array}{l}\text { Schools } \\
\begin{array}{l}\text { School of Architecture, Design and the Built } \\
\text { Environment }\end{array}\end{array}$ & 5 \\
\hline $\begin{array}{l}\text { School of Animal, Rural and Environmental Science } \\
\text { School of Arts and Humanities }\end{array}$ & 4 \\
\hline School of Education & 1 \\
\hline Nottingham Business School & 2 \\
\hline Nottingham Law School & 16 \\
\hline School of Science and Technology & 1 \\
\hline School of Social Sciences & 1 \\
\hline
\end{tabular}

The Challenge Days provide opportunities for students to crowdsource food sustainability solutions both online and additionally in person. The additional element of in-person discussion provides a more authentic environment where students can work in collaboration with others and reflect on their undertaking of practical sustainability-themed work as it happens to inspire further solution-oriented ideas. Participants work in small groups either with those from their own discipline or from another, to brainstorm ideas. They come up with innovative and realistic ideas and suggestions to address the main challenge: how do we feed the world sustainably? Some of the examples presented include developing apps for easy food-identification that could be used globally, instilling policies with strict monitoring for UK supermarkets to donate foods that would otherwise be thrown away (following the introduction of food-waste legislation for French supermarkets), innovative ways for businesses to address social issues in their supply chain, and alternative methods for monitoring marine life and fish supplies.

Feedback from the students about the Challenge Days has, predominantly, been positive. All participants enjoyed the day; more than $50 \%$ expressed that they had enjoyed the allotment session and except for one non-response, all participants said that they would recommend the Challenge Day to their friends. Following the first Challenge Day, students also provided constructive comments on how their experience could be improved. For example, the initial Challenge Day was designed with a similar digital learning environment to the online certificate, and students were encouraged to discuss using the online forums. It was felt that this would encourage greater depth of discussion as the students could pick up 
existing discussion threads and expand on them with new ideas. Feedback indicated however, that participants preferred to have direct conversations with their peers. Hence, during the next Challenge Days, the online environment was used as the teaching medium, and discussions were conducted in-person in class. The feedback following this change has been positive as illustrated below with some quotes from participants when asked 'What was the best part of the Challenge Day?':

'The practical aspect of the foodsharing and the lecture by the gardener was interesting, unique and memorable'

'Outdoor activities, applied practical knowledge'

'The combination of quizzes, discussion and practice'

'Practical experience and gaining the perceptions of students from other courses'

'The whole experience to be honest'

As mentioned earlier, whilst the overall consensus was that the students did enjoy the format of the practical sessions with an initial digital learning experience then practical action, some participants felt the Challenge Days should be run over two days instead of one. It was felt that this would enable them to work intensively on their ideas and bring them into action during the day itself. Others suggested that longer time should be spent focusing on solutions whilst at the allotment. This feedback is being incorporated into planning for future Challenge Days to be undertaken in the following academic year. The value of the Challenge Day as intended by the design and suggested by some of the student feedback, is that it gives students the opportunity to apply sustainability knowledge as they learn it, which should support knowledge retention as well as make sustainability theory less abstract and more meaningful. We have not yet explored the longterm implications of the Sustainability Challenge Days and the applied style of learning, however this is something we might explore in the future.

An additional way in which the participants become co-creators through crowdsourcing of sustainability solutions is through the activities they need to accomplish in the digital environment of the Certificate. As mentioned in Puntha et al (2015) and Molthan et al (2016), to progress through the Certificate, students complete a task in each session. Whilst there are clear academic underpinnings to each task, this has also resulted in a pool of online videos, journal articles, professional and academic reading materials, and blogs that address sustainability problems, that are collated for use as potential teaching materials. These resources include existing sustainability solutions that are being actioned locally in the UK and globally. To date, more than three hundred solutions that have been mapped out on the SiP zeemap based on participant contributions. These learner-generated resources are useful in their spread of disciplines, covering all nine academic Schools and many more disciplines 
across NTU. Bovill et al (2011:9) contend that 'diversity of students' is key to the success of collaborative pedagogical approaches, in this case with students as co-creators of sustainability solutions. The progression of the certificate through the activities and related online research enables students to explore and be inspired by existing solutions from the real world while they develop their own ideas for solutions to the main question: 'How do we feed the world sustainably?'

\section{Development of learner-generated resources}

As mentioned in the previous section, participants must work on their own solutions towards the end of the certificate, culminating in a final project to present their ideas. In response to the desire of students to contribute to solving sustainable challenges, assessment options have now been redesigned so that participants must find a solution for one (small) sustainable challenge with regards to food and their own discipline; this is reflected in new learning outcomes. In order to design their solution they can choose between a video, poster, mood board, or practical project proposal. In the spirit of 'think global, act local' citizenship, which is a theme throughout $\mathrm{SiP}$, the practical project option is particularly encouraged. Within this assessment format participants must propose a plan for a practical action, such as an event, some volunteering or even a business, which relates to food and sustainability. They are encouraged to consider collaboration with a local organisation such as One Nottingham Partnership and to also consider the Nottinghamshire Sustainable Community Strategy and/or Nottingham Plan to 2020 to ensure that their project addresses local need. It is anticipated that in the future, students will take their final projects even further and get more actively involved in making their solutions a reality. Final projects are recycled into teaching materials, for example a video relating to food waste solutions might be shown to business students to provide inspiration on business opportunities relating to food waste. In this way, SiP leads to learner-generated resources to be archived and used by any of NTU's academics.

\section{Fostering sustainability skills through the certificate}

Sustainability is included as one of NTU's 'Graduate Attributes' - the list of qualities, skills and competencies which the institution seeks to facilitate within its students (Puntha et al, 2015). In addition to addressing sustainability, the certificate attempted to address as many of the other attributes as possible to encourage students (and staff) to view sustainability as a relevant subject of study and a tool for developing numerous skills and attributes to support learning beyond sustainability literacy. As the certificate is essentially a stand-alone course, it was also important to draw these connections to support students to articulate their learning gains and transfer them to other contexts. A table of the Graduate Attributes can be found in the Appendix. SiP equips students with transferable skills such as communication and systems thinking as well as skills including citizenship and stewardship, sustainable behaviour, civic engagement, and viable employment for a better quality of life, in line with Armstrong's theory of what encompasses 'sustainability skills' (Armstrong 2011). Both 
hard and soft skills are fostered as participants seek solutions to sustainability challenges.

Hard skills can be defined as 'technical skills that involve working with equipment, data, and software' (Laker and Powell, 2011:112). Soft skills, according to John (2009:20) can be defined as 'people's skills or personality specific skills'. Quoting Hewitt Sean (2008), John (2009:20) further explains soft skills as "non-technical, intangible, personality specific skills" which determines an individual's strength as "a leader, listener and negotiator, or as a conflict mediator". Fenner et al (2005) state that soft skills can be considered as one's ability to initiate a change process from within their workplace. Laker and Powell (2011:113) argue that lack of soft skills transfer results in extremely costly waste of time, energy and money, and that 'employers are better off hiring employees who were already proficient in softskills'.

With respect to soft skills in relation to sustainability, Dale and Newman (2005:351) contend that sustainability literacy 'requires education for a set of critical skills'. A study by Hind et al (2009) found that not only are hard skills inadequate in developing successful leaders, it is more important to further develop the soft skills aspects to ensure responsible leaders.

The certificate offers the hard sustainability skills through its basic concept introduced in session one. Whilst it can be argued that there are five pillars of sustainability (Seghezzo, 2009), the certificate uses the idea of the three pillars of sustainability (environmental, economic and social) (Drexhage and Murphy, 2010) as a starting point for participants who lack knowledge in this area. Those with prior knowledge are encouraged to think beyond the three pillars to political and cultural sustainability as they progress through the sessions.

Subject specific hard skills are introduced in session 2; often students choose to look at the resources provided by other faculties in addition to their own so they acquire a whole range of hard and soft skills such as system thinking (discussed further below) by doing this.

With regards to soft skills, Hunter (2015) and Roorda (2015) argue that soft skills in sustainability consist of various dimensions. The former states that having only strong (hard) knowledge is insufficient: they need to be complemented with 'functional skills' such as global competence (Hunter, 2015). The latter contends that both soft and hard skills are needed for professionals to be competent to address issues related to sustainability, which echoes the views of several scholars (Dale and Newman, 2004; Leal Filho et al 2015).

Systems thinking is a key skill addressed within SiP. Andrews and Higson (2008) have argued that graduates often do not know how to combine different topics or items of information, and may not understand how seemingly different topics or issues might be connected. Roorda (2014:14) however, highlighted that being able to make these connections would show that an individual was thinking and operating from a 'Systems Orientation'. He proposes that 'a sustainably competent professional thinks and acts from a systemic perspective'. This is in line with other scholars who advocate a 'systems thinking' or 'holistic thinking' approach to teaching sustainability (Mochizuki and Fadeeva, 2010; 
Sandri, 2013; Sarabhai, 2014).

Within the certificate, systems thinking is promoted throughout by the interchange of ideas from different disciplines on the same topic of food sustainability. It is also emphasised in particular within the third session of the certificate wherein participants explore the life cycle of a pack of strawberry yoghurt; within this activity they identify the connections between different stages of the food life cycle and how the different disciplines relate to those different stages. For example, they look at how Social Sciences might address retailing and how retailing is to some extent dependent on how a product is transported.

Whereas hard skills are facilitated through the session activities and discussions during the Challenge Days, aspects of participants' soft skills are facilitated through the sharing, discussion and critique of their ideas and work within the discussion forum. Appendix 1 demonstrates some aspects of 'soft skills' that the students can gain from the certificate. As the certificate has adapted the enquiry-based learning model, students need to work out how best to solve the question 'How do we feed the world sustainably?' through the tasks they undertake within their study journey. The soft skills of 'asking awkward questions' and 'questioning practices and systems that are deemed to be unsustainable' (Dale and Newman, 2005; Leal Filho et al 2015) are encouraged from the beginning. Session One requires students to post a question related to sustainability and food in the discussion forum, following a presentation that they have watched, and to then reply to another question from the forum. The purpose is to get them to think critically about their own lifestyle in relation to sustainability and food. Whilst some of the questions students have posted were anticipated by the certificate development team, some students have posted questions which academics have found to be not only interesting but academically challenging to reply to. Such questions have included students displaying systems thinking through their questioning of existing systems and policies.

The hard skills that students gain in the Challenge Days are evidenced through the project presentations delivered at the end of the event. These are video recorded for grading purposes. For ethical reasons, it is not possible to share the ideas of the students in this paper. However, Table 3 below indicates the feedback received from them when asked 'Overall, how informative was the challenge day?' When the students were asked 'How inspired do you feel (about sustainability issues) after participating in the event?', the number of responses was similar, as shown in Table 4 below.

Table 3: Overview of the feedback received from 30 student participants

\begin{tabular}{|l|l|}
\hline Scale (1: Not Informative, 5: Very Informative) & Number of responses \\
\hline 1 & 0 \\
\hline 2 & 0 \\
\hline 3 & 1 \\
\hline 4 & 10 \\
\hline 5 & 19 \\
\hline
\end{tabular}


Table 4: Overview of the feedback received from 30 student participants

\begin{tabular}{|l|l|}
\hline Scale (1: Not Inspired, 5: Very Inspired) & Number of responses \\
\hline 1 & 0 \\
\hline 2 & 0 \\
\hline 3 & 1 \\
\hline 4 & 10 \\
\hline 5 & 19 \\
\hline
\end{tabular}

\section{Limitations and Further Research}

While approximately 3000 students have participated in the SiP so far, this year is the first year that SiP has included practical experiences following recommendations made by student focus groups in 2014 and 2015. Focus groups have not yet been undertaken for the 2015/16 cohort. The feedback included in this paper is based only on students who participated in the Challenge Days as they receive a feedback form following participation. Analysis of the feedback forms indicates that the 2015/16 SiP Challenge Days have constituted a promising pilot project and, therefore, organisation of Challenge Days for the next academic year is already in progress. Furthermore, plans are already underway to include other themes for SiP in addition to the existing theme of food; Clothing and Energy. These additions to the SiP should offer extra dimensions of experience for the participants as well as a richer future dataset.

\section{Conclusion}

The Certificate has achieved success in enabling students to be co-creators in crowdsourcing sustainable solutions, both within the discussion forum and more formally through the final project pieces, which are shared with teaching colleagues. A series of staff development workshops is scheduled for 2015/16 and 2016/17 where participants will be introduced to sustainability concepts, the SiP and the various learner-generated resources. The workshops will be run in enquiry-based learning style within the NTU SCALE-UP rooms ${ }^{2}$.

The certificate is broadly achieving its aspiration of providing students with the skills to solve sustainability challenges; generally this manifests as hard skills through the session activities and project piece, soft skills through discussion and critique of each other's ideas. The certificate has begun to address the practice of skills through the sustainability Challenge Day and this is an element which will be developed further. We have recently embarked upon a new institutional strategy where sustainability features more prominently and this will influence future design of the certificate and its evaluation.

\footnotetext{
2 http://www.ntu.ac.uk/adq/teaching/scale_up/index.html
} 


\section{References}

Andrews, J. and Higson, H. (2008). Graduate employability, 'soft skills' versus 'hard' business knowledge: A European study. Higher education in Europe, 33(4), pp.411-422.

Armstrong, C.M. (2011). Implementing ESD: The potential use of time-honoured pedagogical practice from the progressive era of education

Barresi, P. Focht, W. Reiter, M.A., Smardon, R. C., Humphreys, M., Reiter, K. D. Kolmes, S. A. (2014) Southern New Hampshire University, USA Revealing Complexity in Educating for Sustainability: An Update on the Work of the Roundtable on Environment and Sustainability. $2^{\text {nd }}$ World Symposium on Sustainable Development at Universities, Manchester.

Bovill, C., Cook-Sather, A. and Felten, P. (2011). Students as co-creators of teaching approaches, course design, and curricula: implications for academic developers. International Journal for Academic Development, 16(2), pp.133-145.

Dale, A. \& Newman, L. (2005). Sustainable development, education and literacy. International Journal of Sustainability in Higher Education, 6(4), pp.351-362.

Diamond, S. and Irwin, B. (2013). Using e-learning for student sustainability literacy: framework and review. International Journal of Sustainability in Higher Education, 14(4), pp.338-348.

Drexhage, J. and Murphy, D. (2010). Sustainable development: from Brundtland to Rio 2012. Background paper prepared for consideration by the High Level Panel on Global Sustainability at its first meeting 19 September 2010.

Fenner, R.A., Ainger, C.M., Cruickshank, H.J. and Guthrie, P.M. (2005), "Embedding sustainable development at Cambridge University Engineering Department", International Journal of Sustainability in Higher Education, 6(3), pp. 229-41.

Foresight (2011). The Future of Food and Farming: Final Project Report. The Government Office for Science, London. Available at: http://www.bis.gov.uk/assets/foresight/docs/foodand-farming/11-546-future-of-food-and-farming-report.pdf. [Accessed 11 September 2014].

Hind, P., Wilson, A. and Lenssen, G. (2009). Developing leaders for sustainable business. Corporate Governance: The international journal of business in society, 9(1), pp.720 .

Hunter, B. (2015) Global Competence Amongst Youth is Critical to Achieve Sustainable Development Goals. Available online at http://www.un.org/youthenvoy/2015/07/globalcompetence-amongst-youth-critical-achieve-sustainable-development-goals/ [Accessed $9^{\text {th }}$ Dec 2015].

John, J. (2009). Study on the Nature of Impact of Soft Skills Training Programme on the Soft Skills Development of Management Students, 19-27. 
Laker, D.R. and Powell, J.L. (2011). The differences between hard and soft skills and their relative impact on training transfer. Human Resource Development Quarterly, 22(1), pp.111122.

Leal Filho, W., Manolas, E., \& Pace, P. (2015). The future we want. International Journal of Sustainability in Higher Education, 16(1), 119-129.

Levy, P. and Petrulis, R. (2012). How do first-year university students experience inquiry and research, and what are the implications for the practice of inquiry-based learning?

Studies in Higher Education, 37, (1), 85-101.

Mochizuki, Y. \& Fadeeva, Z. (2010). Competences for sustainable development: Significance and Challenges for ESD. International Journal of Sustainability in Higher Education, 11(4), pp.391-403.

Molthan-Hill, P., Dharmasasmita, A. and Winfield, F.M. (2016). Academic Freedom, Bureaucracy and Procedures: The Challenge of Curriculum Development for Sustainability. In Challenges in Higher Education for Sustainability (pp. 199-215). Springer International Publishing.

Puntha, H., Molthan-Hill, P., Dharmasasmita, A. and Simmons, E. (2015). Food for thought: A university-wide approach to stimulate curricular and extracurricular ESD activity. In Integrating sustainability thinking in science and engineering curricula (pp. 31-47). Springer International Publishing.

Rogers, M., Pfaff, T., Hamilton, J. and Erkan, A. (2015). Using sustainability themes and multidisciplinary approaches to enhance STEM education. International Journal of Sustainability in Higher Education, 16(4), pp.523-536.

Roorda, N. (2016) Management for Sustainable Development, Denmark: River Publishers.

Sandri, O.J. (2013). Threshold concepts, systems and learning for sustainability.

Environmental Education Research, 19(6), pp. 810-822.

Sarabhai, K.V. (2014). ESD and Sustainable Development Goals. Journal of Education for Sustainable Development, 8(1), pp.1-2.

Seghezzo, L. (2009). The five dimensions of sustainability. Environmental Politics, 18(4), pp.539-556. 
Appendix: Table to show where SiP addresses institutional Graduate Attributes

\begin{tabular}{|c|c|c|c|c|c|c|}
\hline \multicolumn{2}{|c|}{ NTU Graduate Attributes } & Session 1 & Session 2 & Session 3 & Session 4 & Final Project \\
\hline \multicolumn{7}{|c|}{ Intellectual Agility } \\
\hline IA1. & $\begin{array}{l}\text { Extensive understanding of their chosen profession or discipline, including the associated } \\
\text { practices, technologies, research, methodologies, values and ethics. }\end{array}$ & & $\mathrm{Y}$ & & & \\
\hline IA2 & $\begin{array}{l}\text { Aptitude for independent, critical thought and rational inquiry, alongside the capacity for } \\
\text { analysis and problem-solving in multiple contexts. }\end{array}$ & \multicolumn{5}{|c|}{ Y - throughout } \\
\hline IA3 & $\begin{array}{l}\text { An enterprising and creative mindset, able to thrive in rapidly changing work and social } \\
\text { environments. }\end{array}$ & & & $\mathbf{Y}$ & $\mathbf{Y}$ & $\mathbf{Y}$ \\
\hline IA4 & Intellectual curiosity, enthusiasm for learning and an aptitude for self-directed learning. & $\mathbf{Y}$ & $\mathbf{Y}$ & $\mathbf{Y}$ & $\mathbf{Y}$ & $\mathbf{Y}$ \\
\hline \multicolumn{7}{|c|}{ Information, Communication and Organisational Skills } \\
\hline ICOS1 & Proficiency in finding, evaluating, analysing and applying data. & & $\mathbf{Y}$ & $\mathbf{Y}$ & $\mathbf{Y}$ & $\mathbf{Y}$ \\
\hline ICOS2 & Digital literacy and the ability to use ICT effectively. & \multicolumn{5}{|c|}{ Y - throughout } \\
\hline ICOS3 & Effective communication skills in spoken, written and visual media. & \multicolumn{5}{|c|}{$\begin{array}{l}\text { Y - written and visual media throughout. Spoken optional for Final } \\
\text { Project. }\end{array}$} \\
\hline ICOS4 & Good team and collaborative working skills. & & & & $\mathbf{Y}$ & Y (optional) \\
\hline ICOS5 & Ability to prioritise, plan and manage work and time. & \multicolumn{5}{|c|}{ Y - throughout. Particularly for final project. } \\
\hline ICOS6 & Capacity to appropriately judge self-efficacy and to give and receive feedback effectively. & $\mathbf{Y}$ & $\mathbf{Y}$ & $\mathbf{Y}$ & & \\
\hline \multicolumn{7}{|c|}{ Global Citizenship } \\
\hline GC1 & $\begin{array}{l}\text { International awareness and openness to the world, based on appreciation of social and } \\
\text { cultural diversity, respect for human rights and dignity. }\end{array}$ & \multicolumn{5}{|c|}{ Y - throughout } \\
\hline GC2 & Understanding and appreciation of social, economic or environmental sustainability issues. & \multicolumn{5}{|c|}{ Y - throughout } \\
\hline
\end{tabular}




\section{Examples}

IA1 Session 2: students access online resources relating to sustainability and food and their discipline and then source some further resources themselves.

ICOS6 Session 1: students are asked to source and post a link and explanatory statement regarding the sustainability of chicken stir fry ingredients to the discussion forum and to comment on someone else's post. 